$\begin{array}{ll} & \text { Etnográfica } \\ \text { etnográfica } & \text { Revista do Centro em Rede de Investigação em }\end{array}$

Antropologia

vol. 19 (1) | 2015

Vol. $19(1)$

\title{
Práticas socializadoras do gosto sexual e do exercício do sexo
}

Socialization practices regarding sexual taste and the exercise of sex

\section{Elias Evangelista Gomes}

\section{(2) OpenEdition}

\section{Journals}

\section{Edição electrónica}

URL: https://journals.openedition.org/etnografica/3899

DOI: 10.4000/etnografica.3899

ISSN: 2182-2891

\section{Editora}

Centro em Rede de Investigação em Antropologia

\section{Edição impressa}

Data de publição: 1 fevereiro 2015

Paginação: 51-75

ISSN: 0873-6561

\section{Refêrencia eletrónica}

Elias Evangelista Gomes, «Práticas socializadoras do gosto sexual e do exercício do sexo», Etnográfica [Online], vol. 19 (1) | 2015, posto online no dia 06 março 2015, consultado o 10 fevereiro 2022. URL: http://journals.openedition.org/etnografica/3899 ; DOI: https://doi.org/10.4000/etnografica.3899

\section{(c) (i) (8)}

Etnográfica is licensed under a Creative Commons Attribution-NonCommercial 4.0 International License. 


\section{Práticas socializadoras do gosto sexual e do exercício do sexo}

\section{Elias Evangelista Gomes}

Este artigo é resultado de um estudo etnográfico que teve como objetivo identificar e analisar as práticas de socialização contemporâneas entre jovens de uma igreja evangélica neopentecostal da cidade de São Paulo, Brasil. Analisam-se as estratégias e as tensões existentes em torno da socialização para a sexualidade. Conceitualmente, discute-se a construção social do gosto sexual e do exercício do sexo, a partir do consumo de mídia pornográfica entre os jovens.

PALAVRAS-CHAVE: socialização, gosto sexual, exercício do sexo, juventude, religião, pornografia.

Socialization practices regarding sexual taste and the exercise of sex - The article is the result of an ethnographic study aimed to identify and analyze contemporary socialization practices among youngsters in a Pentecostal Evangelical Church in the city of São Paulo, Brazil. Socialization regarding sexuality and the strategies and tensions it involves are the main focus of the article. The consumption of pornographic media among these young people allows for the conceptual discussion of sexual taste and the exercise of sex as social constructs.

KEYWORDS: socialization, sexual taste, sexual practice, youth, religion, pornography.

GOMES, Elias Evangelista (eliasgomesbh@yahoo.com.br) - Universidade de São Paulo (USP), Brasil. 


\section{APONTAMENTOS INTRODUTÓRIOS}

Este artigo é resultado de uma pesquisa etnográfica realizada junto aos jovens do templo da Comunidade Evangélica Sara Nossa Terra, localizada na Rua Augusta, no centro da cidade de São Paulo, Brasil. ${ }^{1}$ Durante dois anos de trabalho de campo foram realizadas entrevistas, visitas às casas e aos espaços de lazer que frequentavam na cidade, contatos via redes sociais e acompanhamento contínuo das atividades eclesiais. ${ }^{2} \mathrm{~A}$ investigação apoiou-se em duas questões centrais: (a) quais são as estratégias de socialização desenvolvidas para jovens e pelos jovens?; (b) quais são as tensões existentes em seus processos socializadores?

Os jovens que compuseram a discussão central deste artigo têm entre $18 \mathrm{e}$ 25 anos, são estudantes de cursos preparatórios para ingresso no ensino superior ou de cursos técnicos ou universitários e são majoritariamente moradores da periferia da cidade de São Paulo. ${ }^{3}$ A sexualidade aparece como um dos importantes pontos de tensão no processo de socialização juvenil na igreja. A comunidade de fé constrói um programa de socialização que demarca tempos e modalidades de relacionamentos sexuais, bem como modos de interagir com o outro e consigo. Assim, por meio da interpretação dos dados etnográficos, chegou-se à elaboração conceitual acerca da construção social do "gosto sexual" e do "exercício do sexo" no contexto da socialização vivenciada pelos jovens da igreja evangélica estudada.

\section{A CONSTRUÇÃO SOCIAL DA SEXUALIDADE}

De pronto, é relevante considerar que o contexto vivido pelos jovens pesquisados é pautado pelo avanço da tecnologia e o acesso facilitado pelas diferentes mídias a fontes de informação. Eles vivem na cidade de São Paulo, maior cidade da América do Sul, de economia forte e desigual que influi no estilo de

l Esta pesquisa foi apoiada pela Fundação de Amparo à Pesquisa do Estado de São Paulo (Fapesp), através do processo 07/52292-4.

2 Convém esclarecer que a categoria "jovem” é especialmente uma categoria interna do grupo investigado. Observa-se que eles e elas possuem um conjunto de características em comum: maior tempo livre para o lazer; priorização da escolarização média, técnica e superior; participação em atividades focadas nessa fase da vida denominada "juventude", compartilhando atividades de lazer comuns a outros sujeitos da mesma categoria, mesmo que não evangélicos (ver Gomes 2010a, 2012a).

3 Seus pais não possuem formação superior e recebem baixa ou média remuneração. Os jovens que trabalham, por vezes, ajudam a família, mas não comprometem todo o salário com isso. Podem investir seus ganhos em roupas (não muito caras), formação escolar e atividades de lazer. Antes de ingressarem na Comunidade Evangélica Sara Nossa Terra da Rua Augusta, é comum o trânsito religioso por outras igrejas evangélicas. Este templo específico atrai muitos jovens da periferia por conta das atividades de lazer, festas e eventos que promove e por sua localização em uma das áreas centrais da cidade, em um dos seios da elite econômica paulistana (os Jardins) e de sociabilidade noturna, conferindo aos seus frequentadores certo prestígio (ver Gomes 2010b, 2012b). 
vida, no lazer, na forma de mobilidade urbana e adesão religiosa, bem como nos tipos de equipamentos domésticos adquiridos para uso privado e coletivo. Nesta cidade, como em muitas outras, o apelo ao corpo é exposto nos meios de comunicação e em diversos estabelecimentos - desde a televisão às revistas e filmes eróticos expostos em bancas; desde o acesso à Internet à observação de corpos sexualizados em academias, ruas, festas e escolas. ${ }^{4}$

Gayle Rubin (2003 [1984]) considera que a industrialização e a urbanização na Europa Ocidental e nos Estados Unidos favoreceram as novas formas de organização do Estado, ao mesmo tempo em que reorganizaram as relações familiares gerando outras configurações de gênero, novos processos identitários e sociais e novas formas de conflitos ideológicos e políticos. A autora aponta a emergência de um novo sistema sexual constituído por diferentes pessoas sexuais, populações, estratificações e tensões políticas (Rubin 2003 [1984]). Percebe-se, no caso brasileiro, especificamente no paulistano, que o apelo ao corpo convida os sujeitos a refletirem sobre seus próprios corpos e sobre as formas de equipá-los e manipulá-los, não apenas para a beleza e a saúde, mas também para a sexualidade, ao mesmo tempo em que beleza e saúde estão atreladas às dinâmicas do erotismo. As mídias, a igreja, a família e a escola chamam a atenção para a saúde sexual do corpo. Longe de serem convergentes, por vezes abordam o mesmo tema a partir de categorias de julgamento distintas. ${ }^{5}$

Jeffrey Weeks (2000: 37) aponta que, com o aparecimento da AIDS, as práticas sexuais tornaram-se uma "atividade de alto risco" e uma poderosa metáfora para a cultura sexual na contemporaneidade. A sexualidade saiu da esfera íntima e privada e chegou ao debate público como campo atravessado por relações de poder, a partir das ações do movimento feminista, e como campo de construção de identidades, intermediado pelo movimento homossexual (Heilborn 1999).

Nessa direção, a sexualidade torna-se mais que uma preocupação individual, avançando para uma questão crítica e política. As diferentes instâncias

4 O culto ao corpo tem sido um tema abordado por diferentes autores (Anzai 2000; Castro 2007; Iriart, Chaves e Orleans 2009). Neste artigo, refiro-me ao corpo construído para atrair atenção sexual. O corpo sexualizado é pensado aqui em sua expressão erótica, construído e exposto para apreciação, classificação e julgamento.

5 Em outro artigo pude desenvolver uma argumentação específica sobre a dimensão pedagógica para a sexualidade juvenil na igreja estudada. A saber, é criado um "ambiente de confiança", de modo que o jovem possa expor suas tensões em relação às propostas da igreja para os pastores e jovens líderes. A partir de uma inspiração maussiana (Mauss 2003 [1923-1924]), a cosmologia evangélica para a sexualidade é inserida em um "circuito do cuidado" que envolve confessar o pecado, receber o perdão e não pecar novamente como retribuição ao perdão atribuído pelo Sagrado. Embora as famílias disponham de estratégias para a sexualidade juvenil, é comum que os jovens privilegiem outros sujeitos e instâncias sociais na formação da sexualidade, dentre eles amigos, religião, mídia e escola (ver Gomes $2012 b)$. 
socializadoras disputam o controle das definições, convenções, crenças e comportamentos sexuais. Para Michel Foucault (1998 [1976]), a história da sexualidade é uma história dos discursos sobre a sexualidade e esses discursos configuram-se num corpo de conhecimentos modelador das formas de os sujeitos pensarem o corpo. O dispositivo da sexualidade prolifera, inova, anexa, inventa e penetra nos corpos de maneira detalhada, controlando as populações de modo global.

Foucault (1998 [1976]) argumenta que a regulação social da sexualidade se contextualiza numa "sociedade disciplinar". Assim, não se deve compreender o poder como uma força negativa, baseada meramente na proibição, mas, ao contrário, como positiva, por administrar e orientar os percursos das experiências sociais a serem vividas pelo sujeito. O sexo, observado a partir do conceito de "biopoder", é uma tecnologia da vida, central tanto para a vida individual (corpo do sujeito) quanto para a vida da espécie humana e dos comportamentos populacionais (corpo político).

A socialização para a sexualidade não se restringe à genitalidade ou à primeira relação sexual. É um processo de experimentação pessoal e de impregnação cultural; no tocante à sexualidade, "constitui-se na familiarização de representações, valores", "rituais de interação e de práticas", processo que se acelera na puberdade e na juventude (Heilborn et al. 2006: 35). Grosso modo, a sexualidade deve ser compreendida como uma construção social e histórica, pois a constituição sexual da pessoa é parte de sua constituição geral, uma vez que o sexo a penetra por inteiro.

\section{O REFINAMENTO DO GOSTO}

Jean Anthelme Brillat-Savarin (1995 [1925]), em A Fisiologia do Gosto, aponta alguns aforismos relacionados ao gosto gastronômico. Neles, percebe-se uma clara diferenciação entre aqueles que sabem e os que não sabem comer. Essa diferenciação emerge do julgamento baseado em percepções sociais capazes de classificar, inclusive, quem é a pessoa. A prática de classificar a si mesmo e ao outro não é muito diferente quando o assunto é a sexualidade. Certa literatura antropológica (Facchini 2008; Simões 2004; Uziel 2007) vem mostrando o quanto as experiências sociais no âmbito da sexualidade têm sido difíceis de classificar em termos de categorias que revelem precisamente as vivências dos sujeitos. Grande tem sido a variedade de formas de conceber as experiências na esfera sexual em estudos socioantropológicos, a exemplo de autores que têm atribuído diferentes nomenclaturas para seus entendimentos acerca da sexualidade - tais como script, roteiro e carreira sexuais (Gagnon e Parker 1995; Gagnon 2006; Heilborn et al. 2006) -, na observação do conjunto de experiências do sujeito ao longo de seu percurso sexual, em especial dos jovens. 
Ressalto, na antropologia, a necessidade de se levar a sério aquilo que os sujeitos pesquisados praticam e o que dizem praticar, pois não são meros informantes, mas produtores do que dizem. Levar a sério é reconhecer as teorias nativas sobre o social. $\mathrm{O}$ argumento do antropólogo deve revelar a alteridade e o seu encontro com o argumento nativo. Deve promover um diálogo entre a perspectiva do pesquisador e a perspectiva nativa, confrontando questões, conceitos e análises (Latour 2005).

A partir do disciplinamento antropológico, estabeleci um estranhamento de alguns elementos das falas dos jovens que costumavam ser familiares em conversas sobre sexualidade, tais como "eu gosto de mulher"; "eu gosto de menino"; "eu gosto de homem, mas acho que, um dia, vou casar com mulher"; "já senti atração por mulher, mas eu gosto mesmo é de homem”. Resolvi levar a sério essas expressões, refletir e interpelar teoricamente a categoria "gosto" buscando compreender como esses meninos e essas meninas constroem parte de seus condicionamentos para a vivência da sexualidade.

Para analisar a sexualidade dos jovens é preciso ser eclético, suspender, utilizar e reformular, quando necessário, conceitos e categorias produzidas pelo senso comum e pela teorização clássica e contemporânea nas ciências sociais. Por vezes, é necessário e possível "tropicalizar" conceitos formulados acima da linha do Equador, como é o caso da noção de gosto.

As variações linguísticas do verbo gostar aplicadas à sexualidade remetem às mais diversas possibilidades de práticas de cultura, desde o vestuário, passando pela conjugalidade e interações sociais, chegando às dimensões do corpo e do prazer. O uso das palavras derivadas do verbo gostar - por exemplo: gostoso, gostosão, gostosona, gostosura - diz muito sobre o que pensam as pessoas a respeito de suas experiências sociais e dos demais sujeitos; consequentemente, evidencia uma capacidade corrente e permanente de julgar, classificar e hierarquizar as condutas vividas na disposição sexual. No Brasil, parece-me que as categorias do gosto, enquanto categorias de julgamento, estão embaralhadas entre as categorias da alimentação, tais como comer, lamber, chupar. Por isso, dizer que gosta de algo ou como gosta, ou que os outros gostam ou não, pode revelar modos de hierarquizar, julgar e agir, tanto diante das disposições ofertadas pelas instâncias socializadoras como daquelas que são constituídas ao longo da experiência social do sujeito.

Assim, para a minha formulação acerca do conceito de "gosto sexual" para pensar a socialização da juventude e da sexualidade, busco referências na obra de Pierre Bourdieu (1980, 2008 [1979]), que de forma sistematizada analisa o gosto aplicado às práticas de cultura de classe na Europa, precisamente na França. ${ }^{6}$ Para Bourdieu (2008 [1979]), o gosto é uma construção social

6 Devido aos recortes metodológicos no recolhimento e na análise dos dados etnográficos, não discorrerei sobre diferenças de classe. 
revelada como prática de cultura, resultante de condições específicas de socialização e também das estratégias de sujeitos e grupos para marcar diferenciações e privilégios. Contudo, penso ser possível aproveitar esse construto teórico como instrumento de inspiração, aplicando-o parcialmente às outras modalidades de gosto e práticas culturais. Preliminarmente, pode-se afirmar que o gosto resulta da experiência social do sujeito, de uma estrutura simbólica e de suas oportunidades de aderir ou resistir a um estilo de vida formulado nas diferentes agências, dentre elas a família, a escola, a religião e a mídia (Setton 2002, 2012).

Bourdieu aponta que, para compreender a composição do gosto, deve-se recorrer à história das experiências sociais dos grupos e sujeitos, a fim de se entender as vantagens e as desvantagens materiais e simbólicas que seus gostos assumem. No tocante à minha conceituação do gosto sexual, tenho como referência a fala de um jovem que diz ter "aprendi[do] a gostar de homem" a partir das experiências de sexo com um amigo da família que dormia sempre em sua casa, afirmando ter sido uma experiência marcante de aprendizado da sexualidade e do prazer. Ou ainda, a fala de jovens heterossexuais autodeclarados, que dizem não saber quando começaram a gostar de pessoas do sexo oposto. Essa naturalização do gosto na teoria de gênero tem sido exemplificada a partir dos dispositivos de gênero que condicionam o sujeito desde o nascer. Para os interesses da minha pesquisa, compreendo que os discursos sobre sexualidade expressam as categorias do pensamento que julgam, hierarquizam, classificam e orientam socialmente os gostos sexuais, manifestando-se no corpo, nas interações sociais e no interesse erótico.

É relevante frisar que com a reflexão acerca da noção de gosto sexual não pretendo propor uma substituição dos termos "orientação sexual" e "opção sexual”. Busco, contudo, a partir de dados etnográficos, articular aspectos conceituais e teóricos que contribuam para uma reflexão geral sobre os processos contemporâneos de socialização da sexualidade. Entendo que a noção de gosto aplicada à sexualidade permite discutir, de modo dinâmico e relacional, a flexibilidade, a provisoriedade, a consolidação das experiências sociais dos sujeitos e a fixação da disposição sexual no habitus (Bourdieu 1997). Por meio da reflexão sobre o gosto sexual, é possível identificar algumas nuances e paradoxos da vida social e alguns nexos entre instâncias sociais, sujeitos, história e valores (sentidos e interesses) em suas complexidades, de modo menos estático e institucionalista, mas também menos abstrato e subjetivista.

\section{A ELABORAÇÃO DO EXERCÍCIO}

O gosto sexual materializa-se nas preferências de gênero, nos espaços de sociabilidade frequentados, nas interações sociais, nas performances corporais etc. Expressa-se na preferência de cor, peso, altura, classe social, estilo de vida da 
pessoa, bem como do tipo, tamanho e formato de órgãos sexuais, ou nos meios escolhidos para a vivência da sexualidade (pública e privada), ou ainda nos espaços para os exercícios do prazer (na cama, em casa, na rua, na Internet, em estabelecimentos especializados etc.). ${ }^{7}$ Esses são apenas alguns exemplos de materialização do gosto sexual. Percebe-se, pois, que uma fração significativa dos interesses eróticos e da socialização da sexualidade dirige-se aos corpos dos sujeitos.

Para os evangélicos, cuidar do corpo é como cuidar do espírito, pois o primeiro deve exteriorizar o segundo (Scheliga 2003). A igreja tem ciência de que o corpo pode ser sexualizado para o prazer; por sua vez, os jovens têm ciência de que a igreja (a fé!) é mediadora de parcela considerável das categorias de julgamento, hierarquização e orientação social de suas experiências sexuais. Porém, como veremos, a igreja não é a única instância de elaboração da disposição sexual no âmbito do corpo.

No plano das falas sobre a sexualidade, os jovens pesquisados utilizavam o verbo gostar combinado com o verbo fazer. Disso surgiu a questão: o que é esse "fazer"? Marcel Mauss (2003 [1934]) aponta que os movimentos corporais são resultados de processos educativos nos quais os sujeitos se referenciam em modelos já existentes, imitando determinados condicionamentos. Segundo o autor, para compreender as técnicas do corpo é necessária a confluência das observações e análises sociológicas, biológicas e psicológicas, visto que elas resultam de processos sociais, biológicos e psicológicos.

Para Mauss (2003 [1934]), as técnicas corporais são as maneiras pelas quais os sujeitos se servem de seu corpo. $\mathrm{O}$ autor aponta uma série de técnicas do corpo, tais como as de natação, postura durante a alimentação e modos de andar, descrevendo as diferentes maneiras de conduzir o corpo por distintas gerações, grupos sociais e sociedades. Nessa direção, considera que a variação de "hábitos" ("habitus") não ocorre apenas com os sujeitos e suas imitações, mas, "sobretudo, com as sociedades, as educações, as convivências e as modas, os prestígios" (Mauss 2003 [1934]: 404). Em seus termos, é necessário observar as técnicas corporais e a produção da razão prática coletiva e individual, a fim de observar a alma e suas faculdades de repetição.

Portanto, "fazer sexo" refere-se a uma parte específica da sexualidade; grosso modo, aos exercícios dos órgãos sexuais. Diferente dos termos "ato sexual" e "relação sexual", que parecem definir tradicionalmente um tipo de interação

7 Exemplos de estabelecimentos comerciais especializados que oferecem espaço para o exercício do sexo: motéis, darkrooms, casas de swing, clubes de sexo, saunas, casas de fetiche, cabines eróticas, cinemas pornôs. Além desses, há outros espaços utilizados com frequência para tal fim: banheiros públicos, elevadores, escadas de incêndio, ruas, parques, praças etc. Para uma leitura aprofundada sobre esses e outros estabelecimentos e sociabilidades sexuais, conferir a coletânea organizada por María Elvira Díaz-Benítez e Carlos Eduardo Fígari (2009), intitulada Prazeres Dissidentes. 
entre, no mínimo, duas pessoas, o exercício do sexo pode representar aqueles sujeitos que exercitam seu corpo para o prazer sozinhos, em casal ou em grupo; com humanos, animais ou objetos. Em síntese, conceituo o "exercício do sexo" como o ato de manipulação de trechos do corpo com vistas ao prazer sexual. São conhecimentos técnicos elaborados e vividos pelos sujeitos em um processo de simbolização, que expressam adesões, negociações, resistências e tensões entre diferentes perspectivas institucionais e individuais. Isto é, compreender o exercício do sexo é conhecer e desvelar as formas de aprendizagem da sexualidade e os valores atribuídos ao corpo, bem como as distinções sociais que diferenciam os sujeitos no espaço da sexualidade.

Não é óbvio como "fazer sexo" ou como estimular o corpo para o prazer. A socialização do corpo para o exercício do sexo, bem como da sexualidade como um todo, inicia-se na infância. Contudo, parece que a partir da puberdade as instâncias de socialização (escola, mídia, religião, família - umas mais e outras menos) centram seus esforços em "ensinar o caminho em que se deve andar" na esfera da sexualidade. Os jovens pesquisados relatam que o conhecimento das zonas corporais geradoras de sensações prazerosas intensifica-se na juventude. Para alguns, esse conhecimento do corpo é elaborado de modo individual; para outros, juntamente com os parceiros sexuais ou a partir de informações coletadas em grupos de amigos ou numa esfera difusa e não identificada. De qualquer forma, todas essas interações e formas pedagógicas de conhecimento do corpo são importantes para o refinamento da disposição sexual e da composição do habitus.

As preferências por determinados "exercícios do sexo" podem revelar os "gostos sexuais" dos sujeitos, suas percepções acerca de seu corpo e dos outros, as dinâmicas estabelecidas entre os sujeitos e as diferentes instâncias sociais, bem como os tempos e modos de viver a sexualidade.

\section{O AGENDAMENTO DA SEXUALIDADE}

A partir das falas de jovens, bispos, pastores e líderes de jovens, observa-se um programa institucional de socialização que visa guiar as experiências sociais dos jovens no âmbito da sexualidade. Denomino esta prática como "agendamento da sexualidade”, em uma descrição típica-ideal (Weber 1999 [1920]), com demarcações cronológicas e padrões culturais próprios, por meio dos quais visa-se orientar os esquemas de ação, modos de ser, agir e pensar. Em outras palavras, o agendamento da sexualidade é um programa institucional de socialização da juventude para a vivência da sexualidade.

O não exercício do sexo pré-nupcial é um dos princípios que compõem o agendamento da sexualidade juvenil na igreja. Porém, tanto jovens como adultos explicam o princípio pela negação. "Não fazer sexo antes do casamento" significa que no momento da vida que antecede o evento das núpcias, 
do contrato de casamento ou da "bênção das alianças", há uma interdição a ser incorporada pelas pessoas que sentem atração sexual. O sexo pós-nupcial é uma expectativa fundada em valores e símbolos disponíveis na cultura e mediada pela Bíblia, valendo tanto para meninos como meninas. Contudo, há maior tolerância para com dissidências sexuais dos meninos do que das meninas, fato recorrente em outros grupos sociais.

Para a igreja, as relações sexuais dos evangélicos devem ser "relacionamentos em santidade". É um tipo de relacionamento em que os sujeitos criam as condições para se conhecerem, planejarem o futuro matrimônio e a junção de projetos de vida nos marcos do agendamento da sexualidade; em suma, trata-se de um encontro pautado, sequencialmente, por oração, namoro, noivado e casamento.

As tensões relacionadas ao processo de socialização da sexualidade dos jovens na igreja evangélica aparecem em outras dimensões e práticas de cultura, tal como evidenciado pelo acesso e não acesso às mídias pornográficas e às interações com parceiros sexuais. Escolho este fenômeno como recorte de pesquisa que elucida o "embrolho" da socialização do gosto sexual e dos exercícios do sexo entre os jovens da igreja evangélica.

"Menino [gosta apenas de meninas] - Quando lá em casa não havia Internet, eu tinha mais costume de assistir Cine Privê. No meu quarto e no dos meus irmãos, não tem televisão; então, tinha que assistir na sala. Daí, eu chegava da igreja e sentava no sofá; assistia Zorra Total, Filme, Serginho Groisman, Altas Horas. Aqueles programas todos que passam à noite até a hora de começar o Cine Privê. Lá pela meia-noite, meus pais iam dormir e eu ficava enrolando. Dizia que estava sem sono, aproveitava que no domingo eu podia acordar mais tarde, falava umas groselhas lá. Daí, eu ia abaixando o volume da televisão, abaixando para meus pais não acordarem e estragarem tudo. Ficava com um olho na televisão e outro na porta do quarto. Quando começava o Cine Privê, meu coração disparava de medo de os meus pais virem ver o que estava assistindo. Só que eu assistia só a metade, pois já estava morrendo de sono. Meus pais, do jeito que são, iriam procurar o pastor para falar com ele: 'Meu Deus, pastor, meu filho está vendo filme pornô'. Imagina a cena, minha mãe desesperada, do jeito que é, iria querer me levar na Igreja Universal [risos]. ${ }^{8}$

Elias - Mas você acha isso coisa para levar na Igreja Universal?

Menino - Não, claro que não. Meu, isso faz parte da vida. Como que eu ia aprender a fazer sexo? Tinha que ver uns Cine Privê da vida para

8 "Levar na Igreja Universal" significa que o caso ou problema vivido é muito grave. Há também o termo "levar na igreja", usado em casos como aqueles de pessoas enfermas, que ouvem: "vou te levar ao hospital". 
aprender. Agora eu até estou achando o Cine Privê bem fraquinho [risos]. É sério. Na Internet, tem coisa mais forte." [Entrevista]

"Conectando-me ao relato do jovem citado acima, passo a descrever o filme Click: Chantagem do Sexo, que assisti no programa Cine Band Privê. Numa cena da primeira parte do filme, duas modelos, com faixas de miss, apenas de biquínis, deitam-se, durante uma excursão ao museu, em uma cama que pertenceu a um político famoso. O lobista (personagem principal do filme) que acompanhava a excursão diz que elas não poderiam se deitar ali. Elas o chamam para se deitar também. As modelos se beijam na boca, nos seios, nas costas e na bunda. Desabotoam a calça dele e tiram a calcinha uma da outra. Ele passa a penetrar com seu pênis a vagina da loira e a beijar a ruiva. Duas jovens aparecem e espiam a cena do canto da parede. A cena de sexo é interrompida quando o lobista, com a mão na cabeça, em seu escritório, simboliza que havia apenas sonhado ao cochilar, que se tratava de uma situação imaginária [...]. A primeira cena da segunda parte do filme mostra um dos personagens na cadeia. Um preso antigo, forte, musculoso e viril, em pé, pede a um novato que passe creme em suas costas. Sem jeito, o novo preso aceita o pedido. E a cena termina, insinuando que os dois exercitariam o sexo juntos, mas sem apresentá-lo, ao contrário de cenas entre homens e mulheres, mulheres e mulheres." [Caderno de campo]

O crescimento do cinema pornô, nos anos de 1970, foi acompanhado pela criação de políticas de controle e demarcação de salas especializadas em exibir esse tipo de filme. Com a criação do videocassete, o filme pornográfico torna-se um espetáculo que adentra os lares (Sohn 2008). No Brasil, a indústria pornográfica, potencializada pelas inovações tecnológicas, produz filmes de forma avassaladora. Com um roteiro rápido, poucos atores, cenários e equipamentos, um filme pode ser gravado em poucas horas. Chegam rapidamente ao mercado, não só especializado - locadoras e sex-shops -, mas também ao comércio popular e aos sites da Internet (Díaz-Benítez 2010). Em diferentes lugares na cidade de São Paulo, sejam centros comerciais, calçadas ou pontos de ônibus, é possível observar pequenas grades de exposição ou mesas desmontáveis com lançamentos de filmes internacionais e nacionais "piratas" e, recorrentemente, há nelas espaço para os filmes pornográficos. ${ }^{9}$ Em geral, privilegiam-se os filmes para pessoas que apreciam o sexo oposto; porém, vasculhando-se um pouco os plásticos - porta-DVD -, podem-se encontrar filmes para outros gostos (entre pessoas de mesmo sexo, com transexuais, sexo grupal etc.).

9 No Brasil e também em Portugal, o termo "pirata” é sinônimo de comercialização de cópia não autorizada de produtos e de uso ilegal de material protegido por direitos autorais. 
Mesmo diante de tantos produtos eróticos e pornográficos disponíveis nos locais de passagem (por exemplo, nas bancas de revista da Avenida Paulista, em São Paulo), os jovens da pesquisa acessam pouco o material vendido nas bancas de revista e do comércio popular; alguns apenas observam e desejam comprar, pois são economicamente acessíveis, mas não compram por se sentirem expostos aos olhares de conhecidos e transeuntes, uma vez que o consumo de pornografia pode ser considerado uma transgressão.

"Um menino, acusado pelos irmãos e amigos de gostar de meninos [ser gay, bicha etc.] por conta de sua performance corporal tida como efeminada (mas que afirma nunca ter exercitado o sexo em companhia de outra pessoa do seu sexo e gostar de meninas) disse, hoje, que já assistiu filmes pornôs, comprados pelo pai (não evangélico) e entregues a ele e seus irmãos. Disse que assistiu, mas que se arrepende. Perguntei-lhe se, ao ver o filme, tinha-se excitado mais pelo homem, pela mulher, pelos dois ou se não tinha sentido nada. O jovem respondeu: 'Nem quero me lembrar disso, pois, se lembrar, vou lembrar de coisas que foram ruins para mim.' Nesta mesma semana, outro jovem (que gosta apenas de meninas) disse ter comprado um filme, mas que ficou com medo de ser visto por alguém conhecido e, ainda, teve problemas para guardar, pois poderia ser encontrado pela mãe. Outro jovem (que gosta também apenas de meninas) informou ter visto filmes na casa de amigos de sua antiga igreja, locados por um irmão não evangélico de seu amigo também evangélico." [Caderno de campo]

Possuir computador em casa não é só uma demanda dos jovens, mas das famílias e do Estado que veem nesse equipamento um modo de potencializar a aquisição de novos conhecimentos e promover práticas de lazer, comunicação, educação e formação profissional. A popularização dos computadores e da Internet promove uma importante variação no tipo de consumo de material pornográfico. Há uma tendência de redução no consumo de filmes e produtos eróticos disponíveis na televisão aberta, do tipo Cine Band Privê. Os canais de TV pagos, exclusivos, de pornografia não são muito utilizados por aqueles jovens que moram com a família, tendo em vista os constrangimentos existentes entre os parentes, que ainda consideram a pornografia como uma prática dissidente de prazer.

Assim, as tensões no agendamento da sexualidade do jovem evangélico não se limitam às questões shakespearianas: Ficar ou não ficar? Namorar ou não? Casar ou não? Fazer ou não fazer sexo antes do casamento? A mídia é uma instância provocadora de inúmeras tensões, pois se, por um lado, o computador (e também o celular) pode colaborar para a sociabilidade entre os jovens da igreja, bem como ampliar o acesso a conteúdos bíblicos, por outro, ele marca um novo tempo no consumo da pornografia. Enquanto na época do videocassete 
e dos filmes televisivos os filmes pornográficos eram assistidos de modo privado em aparelhos de uso coletivo, mais recentemente os televisores e os computadores adentraram os espaços tidos como privados, como quartos, salas de estudo e escritórios. Há computadores pessoais no quarto de cada membro da casa, no quarto dos irmãos mais velhos ou daqueles que ajudaram financeiramente na aquisição do equipamento. A televisão continua sendo importante no acesso à pornografia, mas o computador conectado à Internet, tanto para meninos quanto para meninas, facilita o acesso a trechos de filmes pornográficos (daqueles disponíveis no comércio popular, bem como de outros) com menores constrangimentos e riscos de serem descobertos no ato do consumo.

O receio dos jovens de serem descobertos aumenta quando o computador é de uso coletivo da família, um receio ainda mais intenso no caso das meninas. Em outros termos, os constrangimentos acerca do consumo da pornografia são desiguais, havendo mais tolerância com os meninos do que com as meninas. ${ }^{10}$ Nesse sentido, busca-se adquirir conhecimentos técnicos para apagar da memória do aparelho o registro de acesso que possa evidenciar não apenas o desvio no agendamento da sexualidade - seja o da família ou o da igreja como também o gosto sexual e formas de exercício do sexo mais apreciadas pelo sujeito.

"Estratégias identificadas nas falas dos jovens. TV: mudar de canal antes de desligar caso o aparelho, ao ser ligado, possa ir diretamente ao último canal assistido. Computador: apagar histórico de navegação do dia. Se for descoberto, no caso do computador, são utilizados argumentos para despistar o desejo de consumo, dizendo: 'abriu sem querer' ou 'o computador está com vírus', 'foi uma colega que enviou um email e eu abri não sabendo o que era'." [Caderno de campo]

Deve-se acrescentar que o computador não só disponibiliza o contato com a arte erótica, mas possibilita relacionamentos virtuais, por exemplo através de salas de bate-papo sobre sexo e da exibição de performances sexuais, além do acesso a informações eróticas com a finalidade de aperfeiçoar relacionamentos já existentes ou que surgirão. Por meio desses canais virtuais, os jovens aprendem e aperfeiçoam as técnicas de exercício do sexo, de abordar o corpo, sentir

10 Ao longo do trabalho de campo, observei e ouvi as meninas reclamarem sobre certa distribuição desigual dos constrangimentos no combate aos demais "desvios" na expressão da sexualidade. Por mais que a igreja dissesse que tratava todos e todas com igualdade, que "pecado é pecado", "não existe pecadinho e pecadão", elas constatavam as distinções que diferenciavam os "mesmos pecados" de acordo com o fato de serem cometidos por meninos ou meninas. Essas distinções são os valores que conservam a noção de proteção das meninas para que não sejam mal vistas, mas fazem com que muitas delas sintam-se, em algum momento, limitadas na expressividade de suas sexualidades. 
prazer e estimular a libido do parceiro ou da parceira. Assim, o baixo acesso por parte das meninas parece contribuir, parcialmente, para a maior dificuldade nas experiências de prazer, revelando maiores constrangimentos quanto às manipulações do próprio corpo ou do corpo da pessoa com a qual exercita o sexo.

Menina (gosta somente de meninos):

"Informou que viu site pornô apenas uma vez, no computador de seu quarto na companhia do seu namorado. Ela lhe perguntou se via e ele respondeu que sim; ao mostrar o conteúdo, o site ficou gravado no histórico. Segundo a jovem, na tela, apareciam pessoas 'fazendo sexo'. Relata que ficara 'desesperada' e com medo de sua mãe ver o conteúdo." [Caderno de campo, primeiro ano do trabalho de campo]

Mesma menina (continua gostando somente de seu namorado):

"Quase nunca me masturbo. Não há um momento específico. Homem sabe de masturbação desde criança e a mulher demora mais, o que é o que, onde é o que, pois tem mais pudor. Meu namorado me perguntava e eu dizia: 'Não, não gosto desse negócio, para mim não acontece nada e é a maior mentira.' Ele achava muito estranho. Ele ficava me questionando: homem se masturba tanto e por que mulher não se masturba? Depois que eu fui descobrir o que era o que, como era. Daí, hã... [risos] Daí, quando você descobre... [risos] Tem um ano e meio que descobri [idade: 18 anos e meio na época da descoberta]. Tenho, ultimamente, me masturbado mais durante o sexo." [Entrevista no segundo ano da pesquisa]

Mauss (2003 [1934]) alertava que as classificações das técnicas do corpo variavam de acordo com o sexo e a idade. A partir do que já foi elaborado pela antropologia contemporânea, o etnógrafo da sexualidade precisa atentar para outros demarcadores de diferenças. Nos interesses deste estudo, além das diferenças entre meninos e meninas, observa-se uma diferença no consumo de pornografia entre pessoas de gostos dissidentes e não dissidentes. Em geral, os meninos acessam mais que as meninas. Entre os meninos de gosto pelo sexo oposto, o acesso à pornografia ocorre mesmo quando já "fazem sexo" com elas, ou quando não desejam fazê-lo para seguir o agendamento da sexualidade proposto pela igreja. Ou, ainda, mesmo que se pretenda fazê-lo, para esses meninos, o processo de acesso ao corpo das suas namoradas é dificultado por um ritual de relacionamento complexo e demorado, especialmente porque elas não querem ser vistas como "fáceis".

No caso dos meninos que gostam de meninos, também eles acessam os conteúdos pornográficos quando estão em relacionamentos mais fixos ou 
namorando. ${ }^{11}$ Dizem que os acessam num ato contra a vontade, "por impulso", prática também presente nos outros meninos. Ou seja, não queriam acessar, mas, no momento de excitação, acessam. Alguns desses meninos, que estão em processo de reorientação (reconversão) do gosto dissidente para o gosto valorizado pela instituição, às vezes preferem nem se lembrar do assunto, para minimizar a possibilidade de sofrimentos psicológicos. Nesse caso, a culpa parece ser duplicada. Primeiro, como no caso dos meninos de gosto pelo sexo oposto, não desejam mais ver os conteúdos pornográficos para não pecar; segundo, porque além de se considerarem dissidentes pela audiência aos conteúdos pornográficos, acessam conteúdos de sexo entre pessoas do mesmo sexo (homens). Nessa comparação do tipo de vergonha do pecado entre diferentes gostos sexuais, os meninos veem cenas eróticas entre meninas e não sentem o mesmo peso do pecado.

Menina (que gosta de meninos, mas não descarta ficar com meninas um dia):

"Falei com meu namorado: 'Se eu beijar outro cara você ficaria bravo? Faria os seus escândalos? E se eu disser que beijei uma menina', dei o exemplo da minha colega. Ele: 'Ah, aí é outra coisa'. Eu: 'Como assim, é outra coisa?'. [Ele:] 'Mulher, né! Homem até tem uma excitação' [risos]. Acho que já passou pela cabeça dele ficar com outro homem, porque essas coisas passam na cabeça de todo mundo, mas não ficaria, porque não é a cara dele. A gente faz um pré-julgamento. Fulaninho ficaria, mas ele, eu acho que não cederia aos encantos." [Entrevista]

Para os meninos, ver duas mulheres exercitando o sexo é menos transgressivo do que ver dois homens ou um homem (macho) e um travesti. Nessa perspectiva, o desejo do sujeito, bem como a forma de abordar e ver os desejos dos outros, é resultado da socialização de seu gosto sexual. O fato, por exemplo, de um menino ser visto por sua namorada dentro de um conjunto de elementos que para ela representam a heterossexualidade - tais como ser viril no exercício do sexo, penetrá-la, não permitir que ela toque no ânus dele, ter um histórico público de relacionamentos com meninas - fá-la pensar que ele jamais poderá desejar ou se erotizar por um homem; enquanto aqueles que revelam em sua hexis corporal supostos sinais de feminilidade são vistos como possíveis homossexuais e, consequentemente, passivos no exercício do sexo.

A pornografia socializa para o prazer, pois foge da noção do exercício do sexo para reprodução, fixando-se na dimensão do gozo pelo gozo, do prazer

11 Os jovens de gosto pelo mesmo sexo informam que nunca namoraram pessoas da igreja. Eles não apostam tanto em relações duradouras, pois desejam reverter, em algum momento, esse gosto para aquele legitimado. 
pelo prazer. A pornografia expõe referências de posições para o exercício do sexo, modelos de contato entre os sexos, performances sexuais e de gêneros e, por vezes, embaralha categorias socialmente valorizadas pelo grupo de pertencimento do sujeito que a consome.

Nessa direção, a igreja tem como estratégia não apenas associar a pornografia à iniciação sexual precoce, fatalmente atrelada à reprodução, alarmando para o "drama social" da gravidez socialmente considerada precoce, mas também ao desvio dentro do agendamento da sexualidade, tanto temporal (pelo estímulo ao exercício do sexo pré-nupcial com ou sem acompanhante) quanto apreciativo (pela ampliação da percepção dos gostos sexuais). Uma segunda estratégia para refutar o acesso aos conteúdos pornográficos é relacioná-los à prostituição, prática biblicamente reprovada e socialmente polêmica, fazendo o sujeito sentir-se ainda mais distante (desviado) do programa aprovado pela igreja.

Assim, os "filmes educativos" são reconhecidos de forma positiva e negativa. No primeiro caso, os jovens meninos informantes sobre sexualidade, todas as vezes em que foram questionados sobre como aprenderam a "fazer sexo", indicaram um aprendizado ocorrido por meio de filmes eróticos e conteúdos pornográficos. ${ }^{12}$ A percepção negativa da pornografia relaciona-se à introjeção dos argumentos socializadores na tentativa de convencimento para a adesão completa dos jovens ao agendamento da sexualidade. Se, por um lado, o jovem se socializa para o exercício do sexo, dos movimentos a serem desenvolvidos com outra pessoa ou em si mesmo, por outro, considera essa forma de socialização como desviante, sente culpa e vergonha por ter pecado e se prostituído.

Há uma tentativa institucional de relacionar a imaginação erótica e o exercício do sexo sem acompanhante (masturbação individual) a um ato com acompanhante. Assim, o "fazer sexo", acompanhado ou não, é considerado desvio e está no âmbito do real; sexo virtual é "fazer sexo", imaginar é "fazer sexo", masturbar-se é também "fazer sexo", ou seja, qualquer exercício do sexo imaginado ou por toques é "fazer sexo". Afinal, como disse um dos líderes de jovens, "ninguém se masturba pensando no pé da mesa ou na cadeira, masturba-se pensando em outra pessoa". Com isso, quis dizer que quando uma pessoa, fora da conjugalidade, exercita sua imaginação para o prazer sexual no momento da masturbação, é como se se prostituísse com a pessoa imaginada (atrizes e atores pornôs ou modelos de revistas e sites de conteúdos eróticos, parceiro(a), pessoa desejada).

12 Em uma longa gravação para esta pesquisa, um jovem assinalou diversas vezes a pornografia como "filmes educativos" e ouvi o mesmo termo de outros jovens em situações sem gravador. Esta postura revelava pudor, ironia e tentativa de desfocar a noção de pecado atrelada ao consumo de pornografia. 


\section{O CARÁTER SOCIALIZADOR DA PORNOGRAFIA}

“Tanto socializandos como socializadores (jovens e adultos) apresentam uma retórica de que a mídia é a instância que mais influi na antecipação do exercício do sexo entre os jovens. São bastante críticos em relação à erotização das crianças por meio da disponibilização indiscriminada de conteúdos nas mídias. Porém, todos os jovens informantes já entraram em contato, em algum momento, com conteúdos pornográficos. Todos eles consideram o acesso a esses conteúdos como prática dissidente. Argumentam que foram movidos pela curiosidade ou por indicação de alguém (pais e irmãos no caso de meninos e amigos), parceiro sexual (namorado, no caso de uma informante) ou por acesso "sem querer" a links de Internet (para meninos e meninas). Assim, por mais que a pornografia faça parte da "cesta básica" das interdições, os jovens reconhecem seu efeito pedagógico e didático. Os jovens informantes que já exercitaram o sexo com pessoas do mesmo sexo ou do sexo oposto informam que os movimentos do corpo são inspirados nos conteúdos observados na Internet e na TV (filmes, programas em canais abertos e pagos). As técnicas do corpo são inspiradas naquelas utilizadas por mulheres e homens que aparecem realizando striptease, dançando ou fazendo sexo em filmes e programas eróticos. Ainda que os meninos informem com mais frequência acerca desses acessos, jovens de ambos os sexos observam as técnicas desenvolvidas por atores e atrizes como parâmetros para o exercício do sexo realizado com os seus parceiros." [Caderno de campo] ${ }^{13}$

"Um jovem da igreja informara dois sites que acessava na Internet: (a) Pornotube e (b) Garotas da Van. O primeiro site, na página inicial, solicita a idade do sujeito; além disso, oferece três categorias de entrada para visualização: conteúdo hétero, conteúdo gay, todo conteúdo. O jovem sinaliza que utiliza o conteúdo hétero. Na primeira página, há 24 vídeos disponíveis; desses, 23 são apenas hétero, mas há cenas de mulheres se beijando, exercitando o sexo entre si e com objetos. Nos vídeos, homens penetram as mulheres na vagina e no ânus, e uns e outros praticam o sexo oral. Há na lista um vídeo indicado como bissexual, no qual há dois rapazes e uma menina; um penetra a menina e chupa o outro, depois ela chupa o que é penetrado pelo outro. O primeiro grupo de vídeos era o seu preferido. O site Garotas da Van tem três jovens meninas dentro de uma van que circula pelas ruas da cidade de São Paulo. Elas "fazem sexo" com rapazes que entram em contato com os produtores pela Internet. O site oferece vídeos pagos por assinatura mensal, mas os acessados pelo jovem são trechos de vídeos gratuitos,

13 Essa entrada em sites "sem querer" possui uma intencionalidade, sendo também uma forma de tentar atenuar a expressão do desejo. 
episódios em que algum rapaz relata ter sido sorteado a partir do site. Há rapazes que chupam as vaginas, os ânus e os seios das meninas. Geralmente, não há beijos na boca. As três garotas exercitam o pênis dele, se beijam e se lambem. Nesse sentido, o 'lésbico' entra no vídeo como elemento erotizador dos rapazes. Os vídeos são marcados por expressão de alta virilidade por parte dos rapazes, que satisfazem, com isso, uma exigência das meninas. Os rapazes que protagonizam os episódios são, geralmente, jovens ou adultos não muito velhos." [Caderno de campo]

Conversa no MSN (ferramenta de conversação online):

"Elias - Qual é o site que você mais entra?

Menino (gosta de menino) - Sites que tem no Google.

Elias - Mas é de vídeo?

Menino - Sim.

Elias - Quais categorias que você mais curte?

Menino - Oral, anal, esses...

Elias - Tem alguma preferência?

Menino - Militares, bombeiros, pedreiros."

A indústria da pornografia, enquanto discurso obsceno sobre a sexualidade, objetiva a sensibilização erótica do consumidor (ver Leite 2006, 2009; Díaz-Benítez 2010). O sujeito estabelece uma interação com a situação de observar os estímulos eróticos encarnados nos astros pornôs. Por sua vez, o sujeito-consumidor observa a performance erótica na pornografia, tentando se inserir de modo imaginário na cena. Ele tenta se imaginar em uma espécie de interação sexual com a pessoa observada e desejada. Pedagogicamente, os filmes pornográficos tentam colocar cenas em que, por exemplo, aparece um pênis e uma pessoa chupando-o; por vezes, a personagem olha para a câmera, de forma que a pessoa que assiste possa pensar que está sendo chupada. Resumindo, personagens pornôs e consumidores estabelecem uma interação social de produção do prazer; para tanto, produtor-profissional e produtor-consumidor socializam seus corpos para técnicas de exercícios do sexo mais eficientes que visam o prazer.

Os jovens consumidores de pornografia utilizam-na como estímulo erótico para o exercício do sexo via masturbação. A escolha das categorias de filmes depende do gosto socializado ao longo da vida que hieraquiza e qualifica cor de pele e cabelo, gênero, status social, profissão, partes do corpo preferidas, porte físico, tamanhos e formatos de órgãos sexuais. No ato de acesso à pornografia, o consumidor articula suas categorias de julgamento, expressando aquilo que lhe parece bom, bonito e agradável. Põe em prática suas percepções sobre o que aprendeu a valorizar no âmbito da sexualidade, suas expressões do gosto, que podem não ter nada a ver com outros gostos: por exemplo, 
um jovem rico pode se interessar sexualmente apenas por filmes de trabalhadores de profissões populares, embora em termos de interesse de classe, talvez, profissões como executivos e empresários fossem vistas como uma tendência de gosto de classe.

"A pornografia exibe uma variedade de corpos e exercícios que calham para a afirmação e o refinamento dos gostos sexuais dos espectadores, podendo ser escolhidos em um catálogo relativamente grande de categorias de posições e estilos, variando em função de cor, idade, gênero etc. (dupla penetração, anal, oral/boquete, grupal, lésbico, gay, bissexual, travesti, swing, inter-racial, coroas, ninfetas, boys etc.). Esses corpos são apresentados em movimento de exímio equilíbrio e as poucas palavras e os muitos toques buscam orientar e potencializar as sensações de prazer." [Caderno de campo]

Assim, a audiência à pornografia pode se configurar como uma modalidade de exercício do "sexo virtual" entre pessoas que desejam gerar e obter prazer. O exercício do sexo é, portanto, uma performance corporal que depende de encadeamentos sequenciais para a produção do prazer e do gozo. Ao consumir materiais pornográficos, o espectador atribui certo prestígio aos atores e às atrizes por suas performances de alta produtividade do prazer.

Mauss (2003 [1934]) considera que as pessoas tendem a imitar atos bem-sucedidos de outras pessoas nas quais depositam confiança e que têm autoridade sobre elas. Segundo o autor, trata-se de uma imitação prestigiosa, ou seja, uma "noção de prestígio da pessoa que faz o ato ordenado, autorizado, provado, em relação ao indivíduo imitador, que se verifica em todo o elemento social" (Mauss 2003 [1934]: 405). As técnicas corporais prestigiadas inspiram os exercícios do sexo na busca do sujeito por ser bem-sucedido na satisfação de seus desejos.

Entretanto, considero que as técnicas de exercício do sexo com outras pessoas não são imitadas de forma idêntica à apresentada pelas mídias. Primeiro, porque a pornografia trabalha com a noção de exagero (Díaz-Benítez 2010) e, segundo, porque a performance dos exercícios depende também dos parceiros sexuais e não apenas de um único sujeito. Resumindo, para algumas pessoas, as técnicas de exercício do sexo são produtos de imitações, negociações individuais e com os parceiros sexuais, pautadas em técnicas corporais disponíveis no mercado sexual e em sensibilidades corporais socialmente construídas, expressas como gosto, esquemas de classificação, julgamento, percepção e desejo. ${ }^{14}$

14 Essas reflexões decorrem das informações fornecidas pelos jovens acerca dos seus exercícios do sexo, que incluem também negociações com seus parceiros. Por exemplo: há quem tenha revelado não gostar de sexo anal, outros não apreciam bater ou apanhar, havendo ainda diferenças de gostos referentes ao ambiente de exercício do sexo (tais como em casa, na cama ou em público). 
Mesmo sentindo culpa por ter pecado, a maior parte dos jovens consumidores de pornografia vê nela uma possibilidade educativa. Contudo, a pornografia é encarada como desvio no programa institucional de socialização, no agendamento da sexualidade. Primeiro, como desvio temporal, uma "queima de etapa" que pode adiantar a introdução do jovem no exercício do sexo pré-nupcial com parceiros. Segundo, como desvio apreciativo, porque no programa de socialização não há espaço para a prostituição e porque a pornografia pode ampliar a percepção a respeito dos tipos de gostos sexuais possíveis, tanto referentes às técnicas de posições sexuais, bem como aos tipos de parceiros (por exemplo, os filmes de sexo entre pessoas de mesmo sexo).

\section{A CONFIGURAÇÃO DAS CATEGORIAS}

$\mathrm{Na}$ fala dos jovens, as categorias de gênero, sexuais e corporais entrelaçam-se o tempo todo e a cada momento. Suas experiências sociais e modos de ser, sentir, estar ou experimentar as categorias de gênero (masculinidade e feminilidade), de orientação sexual (heterossexual, homossexual, bissexual) e condição (passivo, ativo, versátil/“totalflex"), ${ }^{15}$ ou de transitar por esses ou outros gostos sexuais, dependem da socialização da sexualidade influenciada por diferentes instâncias. Essas negociações baseiam-se em representações sobre as categorias disponíveis no ambiente social, principalmente no tipo de combinação que o sujeito faz entre o social e suas sensibilidades individuais e corporais. Citemos dois casos.

1) Menina que gosta de meninos, mas eventualmente pode gostar de meninas:

"Sempre refutou o exercício do sexo anal e já propôs ao namorado penetrá-lo para ele entender o impacto da penetração em seu corpo. Ele não aceitou, pois disse que isso não é coisa de homem. Ela lhe disse que a diferença entre os dois é apenas essa e que o tamanho do ânus de ambos é o mesmo; a dor independe do gênero. Em entrevista, ela diz: 'Eu sempre ouvi que a igreja é contra a homossexualidade. Eu convivo com pessoas que ficam com homens, mulheres que ficam com mulheres e são pessoas como as outras. Tudo bem, vai contra a lei da natureza. Mas, quem disse que a natureza é homem e mulher? Se está acontecendo é porque é da natureza. Ou são robôs que estão fazendo sexo? Até os animais têm relações homossexuais. Eu não gosto de pensar de forma preconceituosa. Eu convivo bem. Eu acho muito estranho, principalmente entre homem, pelo fato de eu associar ao

15 “Totalflex" faz menção a um tipo de automóvel que aceita como combustível tanto o álcool quanto a gasolina. No contexto sexual, refere-se tanto àqueles que são assinalados como bissexuais, quanto àqueles que cumprem as posições de passivo e ativo. 
sexo anal. Quando eu penso em dois homens, já penso: sexo anal. Como para mim é um tabu, aí eu acho estranho. Quando eu deixo de associar a isso, é tranquilo. Gay não vai namorar para ficar de mãozinha dada e dando beijinho. Os caras estão namorando porque estão pegando um ao outro. Eu já penso: Meu Deus, como pode? Com mulher, é diferente. Porque não tem esse problema comigo de pode e não pode. Daí é uma questão delas.'” [Caderno de campo]

2) Menino que "atualmente" gosta de meninos, mas pretende se casar com uma menina:

"Diz que achava muito estranho o sexo anal, por conta da dor e por receio de se confundir com mulher, pois em sua representação inicial é a mulher que é penetrada. Segundo ele, nos três primeiros meses de exercícios do sexo em parceria com outros meninos e homens, ele 'brochava'. A partir do contato com homossexuais mais velhos, passou a entender que ele poderia articular uma masculinidade viril a um exercício do sexo tanto na posição passiva como ativa. 'A gente aprende a fazer sexo com homem fazendo e ouvindo o que os amigos com mais experiências dizem, pois não é óbvio, nenhum menino sabe que tem que fazer a chuca (modalidade de higienização do ânus); isso se aprende com os amigos. Por isso que eu digo que ser gay é uma experiência de longo prazo, não é como outra experiência qualquer'. Numa outra situação, o jovem informou: 'Acho estranho bater, cuspir, mas esse menino da Igreja Quadrangular com quem estou ficando gosta disso; estou aprendendo ainda, estou aprendendo com ele'." [Caderno de campo]

De modo que aqueles meninos de gosto por pessoas do mesmo sexo, compreendidos como dissidentes no agendamento da sexualidade, que desejam afirmar certa virilidade, podem encontrar dificuldades em seus relacionamentos por conta das marcas sociais impregnadas em suas masculinidades. Essas dificuldades podem surgir pelo fato de terem subjetivado as representações que diferenciam posições de gênero no exercício do sexo (tais como passivo, ativo ou versátil/“totalflex"), ao passo que o caso da menina evidencia o quanto as sensibilidades corporais e as experiências de dor podem influir na percepção, aceitação e estranhamento do outro; por exemplo, do gosto sexual entre meninos.

O sexo, nesse contexto, adquire um sentido mais preciso, referindo-se "às diferenças anatômicas entre homens e mulheres, a corpos marcadamente diferenciados e ao que nos divide e não ao que nos une" (Weeks 2000: 42). Os jovens evidenciam que as diferenciações de gênero estão ramificadas no corpo. Contudo, as partes interditas e autorizadas para toque, penetração, carícias etc. não se limitam ao gênero, mas relacionam-se a uma dimensão do gosto que é baseada também em sensibilidades corporais. 
Em parte movidos por um modelo dicotômico de construção social das categorias de julgamento sobre gênero, sexualidade e corpo, os jovens vivenciam conflitos temporários ou duradouros em suas experiências de socialização do gosto sexual. Nesse sentido, o gosto sexual - as categorias de apreciação, classificação e ação sobre a sexualidade - pode se revelar no tipo de relacionamento e no modo de perceber os outros e a si mesmo, revelar preferências de exercício do sexo e formas de manipulação do corpo para o prazer.

Bourdieu considera que o gosto se configura como uma disposição socialmente construída para "diferenciar" e "apreciar", para estabelecer e marcar diferenças, expressando-se na operação de "distinção". Segundo o autor, o gosto orienta o sujeito para posições sociais ajustadas ao grupo, "para as práticas ou bens que convêm aos ocupantes dessa posição, que lhes 'ficam bem'” (Bourdieu 2008 [1979]: 434). Assim, na minha conceituação, o gosto sexual depende das negociações entre representações coletivas e individuais, bem como da capacidade do indivíduo para articular as representações e práticas disponíveis nos mercados de gênero e sexo, além daquelas que podem ser construídas por si mesmo.

O gosto como uma manifestação das representações humanas reflete a ideia de que as instâncias e os sujeitos da socialização constroem socialmente as noções acerca do corpo, do sexo e do gênero. Assim, o gosto sexual é uma manifestação das construções sociais que o indivíduo e a sociedade, dialeticamente, estabelecem e hierarquizam, legitimando ou não aqueles gostos que são mais ou menos legítimos.

\section{APONTAMENTOS FINAIS}

A variedade de usos do verbo gostar observada na fala dos informantes chamou-me a atenção, lembrando-me ainda que o mergulho teórico nas práticas que envolviam tal verbo poderia revelar as conexões e desconexões em relação a distintos programas de socialização e modelos de relacionamentos sexuais, bem como modos de fé, para conceber a apreciação sexual. Podem-se observar modos de agir e reagir às práticas de socialização disponibilizadas e modos próprios de os jovens se socializarem. Logo, o gosto parece ser uma categoria detonadora e mediadora do que se pode denominar por carreira, percurso, ou script e roteiro sexual; a partir dele constroem-se essas experiências e é nelas que ele se refina.

Os gostos sexuais e os exercícios do sexo delineiam-se ao longo do processo de incorporação das categorias de apreciação, classificação e ação do sujeito, isto é, no seu contato socializador com as instituições e com os demais sujeitos, suas histórias e seus valores (interesses e sentidos) atribuídos à sexualidade. Em outras palavras, numa lógica relacional de análise das diferenciações simbólicas, podemos pensar o gosto sexual e o exercício do sexo como aspectos 
disposicionais elaborados em um processo de domesticação dos interesses sexuais, em um processo de educação do corpo e, sobretudo, a partir das permanentes estratégias distintivas dos diferentes sujeitos e instâncias sociais.

O gosto sexual e os exercícios do sexo derivam de uma rede de influências culturais e são construídos na dialética entre sujeito e instâncias sociais, sendo as fontes de influência, por vezes, muito difíceis de denominar. Essa rede de influências culturais sobre a sexualidade é formada pelas diferentes instâncias com as quais o sujeito tem contato, não se limitando à família, à religião e muito menos à escola. Estas três instâncias têm como mérito o fato de serem organizadoras do conhecimento acerca das diferentes esferas da vida; porém, no tocante à sexualidade, uma mídia disponível na Internet, ou uma banca de revistas ou de filmes, ou um programa de TV, ou ainda um grupo de amigos, podem incidir com mais impacto nos percursos sexuais dos sujeitos pesquisados.

Por consequência, o gosto sexual e os exercícios do sexo são constituídos, significativamente, nas experiências socializadoras e resultam de um processo educativo, na maior parte das vezes, "homeopático". Assim, o fato de o sujeito ter nascido em um lar evangélico contrário às dissidências sexuais e ter a igreja evangélica como fonte de influência sobre diversas condutas pode criar nele predisposições para gostar de certos comportamentos na esfera erótica; contudo, esses registros não são definidores do gosto sexual em todos os sujeitos. Ou seja, a influência cultural da igreja evangélica sobre a sexualidade de sua comunidade de fiéis é quase sempre parcial, pois disputa com outras instâncias - neste caso, com a mídia e grupos de amigos - a socialização dos sujeitos.

A igreja propõe um agendamento da sexualidade juvenil, uma forma própria de conceber as etapas e atribuir os significados. A socialização baseia-se na tentativa de transmitir e incorporar as disposições de habitus que se manifestam como estilo de vida.

Os jovens recordam-se de poucos elementos precisos em relação a quando e como incorporaram seus modos de ser, pensar e agir, seus modos de perceber, classificar, julgar e imaginar, suas disposições de habitus para a prática da sexualidade. Em outros termos, naturalizam a sociogênese, a história da sexualidade deles mesmos. Nesse sentido, no diálogo com os jovens, percebi que a pornografia nem sempre era citada de imediato como fonte educativa mas, no aprofundamento das questões, os jovens mostravam que ela era orientadora de parcelas de seus modos íntimos de conhecer, conceber e viver dentro e fora dos limites e possibilidades do agendamento da sexualidade proposto pela igreja e pela família. Tanto para meninos quanto para meninas, mais para eles e menos para elas - esses jovens que vêm crescendo no ambiente de difusão tecnológica, de conexão à Internet, de privatização e individualização dos computadores -, a pornografia está parcialmente presente na socialização da maioria deles. Não é a única fonte de composição do gosto e das técnicas para o exercício do 
sexo, mas é uma instância educacional do corpo, um vetor marginal, na maior parte das vezes secreto, da construção social da sexualidade na relação consigo mesmo e na projeção do uso do corpo para viver a sexualidade com parceiros e parceiras.

Nesse sentido, como Bourdieu (1997) nos alertou, o habitus nunca é um sistema de destino final; por sua vez, as disposições da sexualidade são negociadas no encontro com o outro, reformulando o esquema geral de percepção do gênero, da sexualidade e do corpo. No contexto vivido pelos jovens desta pesquisa, pode-se afirmar que as experiências sociais apontam para uma hibridação das disposições do habitus, cujo resultado depende das combinações entre o social e o individual. O uso do adjetivo "híbrido" na esfera da socialização (Setton 2012) busca apenas adiantar que as experiências sociais dos jovens são ora convergentes, ora dissidentes. Não se pode falar de reprodução total das disposições propostas pela igreja, nem de uma ruptura total. O mesmo vale para a audiência à pornografia. Exercícios do sexo prestigiados pelo indivíduo na escolha de filmes e conteúdos pornográficos não significam absorção das performances sexuais midiatizadas como prática na relação com outras pessoas. Tendo em vista que a pornografia socializa, porém, trata-se também de uma socialização parcial, pois disputa prestígio, distinção, reconhecimento e valores com outras informações e formas de pensamento difundidas por outras instâncias sociais e sujeitos.

Portanto, no âmbito da sexualidade, pode-se pensar que os sujeitos se distinguem pelas distinções que operam, a partir dos gostos que interiorizaram e estão em permanente construção. Por intermédio dessas distinções, os sujeitos constroem suas aproximações e afastamentos dos demais sujeitos, definem aqueles que serão "salvos por Jesus Cristo" e os que não serão, os que são adequados e os inadequados. Contudo, no que tange ao erotismo, muitos não estão imunes ao estranhamento de se verem excitados por gostos tidos como dissidentes pela instituição religiosa. 


\section{BIBLIOGRAFIA}

ANZAI, Koite, 2000, "O corpo enquanto objeto de consumo", Revista Brasileira de Ciências do Esporte, 21 (2-3): 71 1-76.

BOURDIEU, Pierre, 1980, Questions de sociologie. Paris, Les Editions de Minuit.

BOURDIEU, Pierre, 1997, Méditations pascaliennes. Paris, Seuil.

BOURdieu, Pierre, 2008 [1979], A Distinção: Crítica Social do Julgamento. Porto Alegre, Editora Zouk; São Paulo, Edusp.

BRILlAT-SAVARIN, Jean Anthelme, 1995 [1825], A Fisiologia do Gosto. São Paulo, Companhia das Letras.

CAStro, Ana Lúcia de, 2007, Culto ao Corpo e Sociedade: Mídia, Estilos de Vida e Cultura de Consumo. São Paulo, Fapesp/Annablume.

DÍAZ-BEnÍTeZ, María Elvira, 2010, Nas Redes do Sexo: Bastidores e Cenários do Pornô Brasileiro. Rio de Janeiro, Jorge Zahar Editor.

DíAZ-BEníteZ, María Elvira, e Carlos Fígari (orgs.), 2009, Prazeres Dissidentes. Rio de Janeiro, Garamond.

FACCHINI, Regina, 2008, Sopa de Letrinhas? Movimento Homossexual e Produção de Identidades Coletivas. São Paulo, Garamond.

FOUCAUlT, Michel, 1998 [1976], História da Sexualidade I: A Vontade de Saber. Rio de Janeiro, Edições Graal.

GAGNON, John, 2006, Uma Interpretação do Desejo. Rio de Janeiro, Garamond.

GAGNON, John, e Richard PARKER, 1995, "Conceiving sexuality”, em Richard Parker e John Gagnon (orgs.), Conceiving Sexuality. Nova Iorque, Routledge, 3-16.

GOMES, Elias E., 2010a, "In the church and the street: Reconfigurations of ways of thinking about affective and sexual desire for people of the same sex", Virtual Brazilian Anthropology, 7 (1): 191-220.

GOMES, Elias E., 2010b, "A socialização no aprisco do Senhor", Cadernos do CERU, l (2): 281-304.

GOMES, Elias E., 2012a, "Nas tramas da socialização: uma análise socioantropológica sobre sexualidade juvenil na religião", Cadernos Cenpec, 2 (2): 65-87.

GOMES, Elias E., 2012b, "Festa e pós-festa: a socialização de jovens evangélicos na metrópole”, em Luiz Mello et al., Questões de Sociologia: Debates Contemporâneos. Goiânia, Cânone Editorial, 51-71.

HEILBORN, Maria Luiza, 1999, "Construção de si, gênero e sexualidade”, em Maria Luiza Heilborn (org.), Sexualidade: O Olhar das Ciências Sociais. Rio de Janeiro, Jorge Zahar Editor, 40-58.

HEILBORN, Maria Luiza, et al., 2006, O Aprendizado da Sexualidade: Reprodução e Trajetórias Sociais de Jovens Brasileiros. Rio de Janeiro, Garamond.

IRIART, Jorge Alberto B., José Carlos CHAVES, e Roberto G. de ORLEANS, 2009, "Culto ao corpo e uso de anabolizante entre praticantes de musculação", Cadernos de Saúde Pública, 25 (4): 773-782.

LATOUR, Bruno, 2005, Reassembling the Social: An Introduction to Actor-Network Theory. Oxford, Oxford University Press.

LEITE, Jorge, 2006, Das Maravilhas e Prodígios Sexuais: A Pornografia Bizarra como Entretenimento. São Paulo, Fapesp/Annablume. 
LEITE, Jorge, 2009, "A pornografia 'bizarra' em três variações: a escatologia, o sexo com cigarros e o 'abuso facial'”, em María Elvira Díaz-Benitez e Carlos Fígari (orgs.), Prazeres Dissidentes. Rio de Janeiro, Garamond, 509-536.

MAUSS, Marcel, 2003 [1923-1924, 1934], Sociologia e Antropologia. São Paulo, Cosac Naify. RUBIN, Gayle, 2003 [1984], "Pensando sobre sexo: notas para uma teoria radical da política da sexualidade", Cadernos Pagu, 21: 1-88.

SCHeligA, Eva, 2003, Sobre a Conversão ao Pentecostalismo em Unidades Penais. Florianópolis, Departamento de Antropologia, col. Antropologia em Primeira Mão.

SETTON, Maria da Graça Jacintho, 2002, "Família, escola e mídia: um campo com novas configurações", Educação e Pesquisa, 28 (1): 107-1 16.

SETTON, Maria da Graça Jacintho, 2012, Socialização e Cultura: Ensaios Teóricos. São Paulo, Annablume.

SIMÕES, Júlio Assis, 2004, "Homossexualidade masculina e curso da vida: pensando idades e identidades sexuais”, em Adriana Piscitelli et al. (orgs.), Sexualidade e Saberes: Convenções e Fronteiras. Rio de Janeiro, Garamond, 415-447.

SOHN, Ann-Marie, 2008, "O corpo sexuado", em Alain Corbin, Jean-Jacques Courtine e Georges Vigarello (orgs.), História do Corpo 3 - As Mutações do Olhar: O Século XX. Petrópolis, Vozes.

UZIEL, Ana Paula, 2007, Homossexualidade e Adoção. Rio de Janeiro, Garamond.

WEBER, Max, 1999 [1920], Economia e Sociedade: Fundamentos da Sociologia Compreensiva. Brasília, Editora UnB; São Paulo, Imprensa Oficial do Estado de São Paulo.

WEEKS, Jeffrey, 2000, “O corpo e a sexualidade”, em Guacira Lopes Louro (org.), O Corpo Educado. Belo Horizonte, Autêntica, 35-81. 